\title{
Urocortin 3 transgenic mice exhibit a metabolically favourable phenotype resisting obesity and hyperglycaemia on a high-fat diet
}

\author{
P. M. Jamieson • M. E. Cleasby • Y. Kuperman • N. M. Morton • P. A. T. Kelly • \\ D. G. Brownstein - K. J. Mustard • J. M. Vaughan • R. N. Carter • C. N. Hahn • \\ D. G. Hardie • J. R. Seckl • A. Chen • W. W. Vale
}

Received: 15 March 2011 /Accepted: 26 April 2011 /Published online: 11 June 2011

(C) The Author(s) 2011. This article is published with open access at Springerlink.com

\begin{abstract}
Aims/hypothesis Urocortins are the endogenous ligands for the corticotropin-releasing factor receptor type 2 (CRFR2), which is implicated in regulating energy balance and/or glucose metabolism. We determined the effects of chronic CRFR2 activation on metabolism in vivo, by generating and phenotyping transgenic mice overproducing the specific CRFR2 ligand urocortin 3.

Methods Body composition, glucose metabolism, insulin sensitivity, energy efficiency and expression of key metabolic genes were assessed in adult male urocortin 3 transgenic mice $\left(U c n 3^{+}\right)$under control conditions and following an obesogenic high-fat diet (HFD) challenge.
\end{abstract}

Electronic supplementary material The online version of this article (doi:10.1007/s00125-011-2205-6) contains supplementary material, which is available to authorised users.

\footnotetext{
P. M. Jamieson $(\bowtie) \cdot$ N. M. Morton • D. G. Brownstein •

R. N. Carter · J. R. Seckl

Centre for Cardiovascular Science,

The Queen's Medical Research Institute, University of Edinburgh,

47 Little France Crescent,

Edinburgh EH16 4TJ, UK

e-mail: Pauline.Jamieson@ed.ac.uk
}

\author{
M. E. Cleasby \\ Department of Veterinary Basic Sciences, \\ Royal Veterinary College,
}

London, UK

Y. Kuperman · A. Chen

Department of Neurobiology, Weizmann Institute of Science,

Rehovot, Israel

P. A. T. Kelly

Centre for Cognitive and Neural Systems,

University of Edinburgh,

Edinburgh, UK
Results $\mathrm{Ucn}^{+}$mice had increased skeletal muscle mass with myocyte hypertrophy. Accelerated peripheral glucose disposal, increased respiratory exchange ratio and hypoglycaemia on fasting demonstrated increased carbohydrate metabolism. Insulin tolerance and indices of insulinstimulated signalling were unchanged, indicating these effects were not mediated by increased insulin sensitivity. Expression of the transgene in $\mathrm{Cr} f r 2$ (also known as $C r h r 2$ )-null mice negated key aspects of the $U c n 3^{+}$phenotype. $U c n 3^{+}$mice were protected from the HFD-induced hyperglycaemia and increased adiposity seen in control mice despite consuming more energy. Expression of uncoupling proteins 2 and 3 was higher in $U c n 3^{+}$muscle, suggesting increased catabolic

K. J. Mustard • D. G. Hardie

Molecular Physiology, College of Life Sciences,

University of Dundee,

Dundee, UK

J. M. Vaughan • W. W. Vale

The Clayton Foundation Laboratories for Peptide Biology,

Salk Institute for Biological Studies,

La Jolla, CA, USA

C. N. Hahn

Royal (Dick) School of Veterinary Studies,

University of Edinburgh,

Edinburgh, UK 
processes. IGF-1 abundance was upregulated in $U c n 3^{+}$ muscle, providing a potential paracrine mechanism in which urocortin 3 acts upon CRFR2 to link the altered metabolism and muscular hypertrophy observed.

Conclusions/interpretation Urocortin 3 acting on CRFR2 in skeletal muscle of $\mathrm{Ucn}^{+}$mice results in a novel metabolically favourable phenotype, with lean body composition and protection against diet-induced obesity and hyperglycaemia. Urocortins and CRFR2 may be of interest as potential therapeutic targets for obesity.

Keywords CRFR2 - Energy balance - Glucose uptake - IGF-1 · Obesity $\cdot$ Skeletal muscle $\cdot$ Transgenic mice $\cdot$ Urocortin 3

$\begin{array}{ll}\text { Abbreviations } \\ \text { AMPK } & \text { AMP-activated protein kinase } \\ \text { CRFR2 } & \text { Corticotropin-releasing factor receptor type 2 } \\ \text { GTT } & \text { Glucose tolerance test } \\ \text { HFD } & \text { High-fat diet } \\ \text { ITT } & \text { Insulin tolerance test } \\ \text { LFD } & \text { Low-fat diet } \\ \text { mTOR } & \text { Mechanistic target of rapamycin } \\ \text { p70S6 } & \text { p70 S6 kinase } \\ \text { PAS } & \text { Periodic acid-Schiff's reagent } \\ \text { PEPCK } & \text { Phosphoenolpyruvate carboxykinase 1 } \\ \text { RER } & \text { Respiratory exchange ratio } \\ U c n 3^{+} & \text {Urocortin 3 transgenic mice } \\ \mathrm{UCP}^{\dot{V} C \mathrm{CO}_{2}} & \text { Uncoupling protein } \\ \dot{V} \mathrm{O}_{2} & \text { Rate of carbon dioxide production } \\ & \text { Rate oxygen uptake }\end{array}$

\section{Introduction}

Urocortins are the endogenous ligands for the corticotropinreleasing factor receptor type 2 (CRFR2) [1-5]. Together with corticotropin-releasing factor, urocortins are important regulators of neurohormonal responses to stress [6], integrating adaptive changes in energy flux, and glucose and lipid metabolism [7]. However, chronic stress has been linked to an increased risk of the metabolic syndrome and its components (type 2 diabetes mellitus, dyslipidaemia, hypertension, obesity, atherosclerotic heart disease) [8].

Significant roles for CRFR2/urocortins in regulating metabolism have indeed been identified. Crfr2 (also known as $C r h r 2$ )-null mice resist high-fat diet (HFD)-induced obesity and insulin resistance, effects thought to be primarily centrally mediated, with increased sympathetic activity increasing thermogenesis in brown adipose tissue and hence the metabolic rate $[9,10]$. Intriguingly, however, urocortins are also present at high levels in peripheral metabolic tissues, including skeletal muscle [11, 12], implying that these 'stress regulators' have local peripheral as well as central metabolic actions.

In vitro, skeletal muscle CRFR2 stimulates futile substrate cycling between de novo lipogenesis and lipid oxidation, with a requirement for glucose metabolism and AMP-activated protein kinase (AMPK) signalling [13]. This has spawned suggestions that CRFR2 agonists may protect muscle from excessive intracellular lipid storage and thus from lipotoxicity-induced insulin resistance. However, Ucn2-null mice are protected against diet-induced obesity, with increased insulin sensitivity in skeletal muscle, perhaps due to absence of paracrine antagonism of insulin by urocortin 2 [11]. Ucn3-null mice are also protected from glucose intolerance [14], yet pancreatic urocortin 3 leads to enhanced beta cell insulin production [12]. Thus, although urocortins are clearly potent regulators of glucose metabolism, underlying mechanisms and key tissue(s) of action are various, and the predominant effects unclear.

The necessary pharmacological studies of urocortin administration in vivo have to date only involved shortterm treatments due to experimental constraints. Urocortin 3 is the most specific ligand known for CRFR2 $[4,5]$. To model the effects of chronic pharmacological CRFR2 activation on metabolism in vivo, we exploited this specificity, and generated and phenotyped a transgenic mouse overexpressing Ucn3.

\section{Methods}

Production of transgenic mice The Ucn3 transgene $\left(U c n 3^{+}\right)$was constructed by ligating the mouse $U c n 3$ open reading frame [4] into the EcoRI restriction site of the pBROAD3 vector (InvivoGen, San Diego, CA, USA) (Fig. 1a), placing it downstream of the mouse Rosa26 (also known as Gt(ROSA)26Sor) promoter and upstream of a human $\beta$-globin polyA signal. The expression cassette was injected into the pronucleus of fertilised $(\mathrm{C} 57 \mathrm{BL} / 6 \times \mathrm{BALB} / \mathrm{c})$ F1 mouse oocytes. Mice were genotyped by PCR of genomic DNA. Mouse Ucn3-specific sense (5'-ATGACAAC CAAACGCACCTCCAGA-3') and human $\beta$-globin-specific antisense (5'-GGCCCTTCATAATATCCCCCAGTT-3') primers resulted in a $450 \mathrm{bp}$ transgene-specific amplification product. Five founder animals were identified. Transgene expression was quantified in F3 generations. The line with highest expression was used for subsequent analyses. Crfr2null mice [15] were crossed with $U_{c n} 3^{+}$mice for two generations to generate homozygous $C r f r 2$-null mice carrying the $\mathrm{Ucn}^{+}$transgene for some experiments.

Animal husbandry Mice were housed in temperature- and lighting-controlled rooms (lights on for $12 \mathrm{~h}$ ) with free access to laboratory chow and water except where stated. 
a

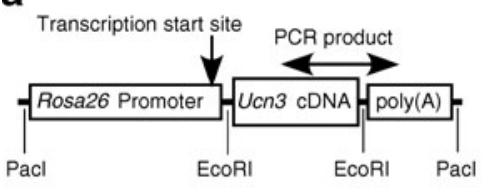

b

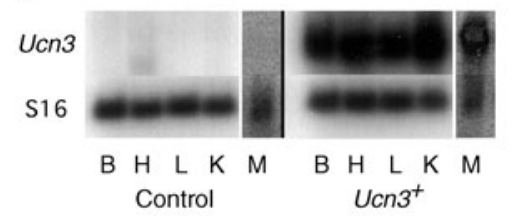

f

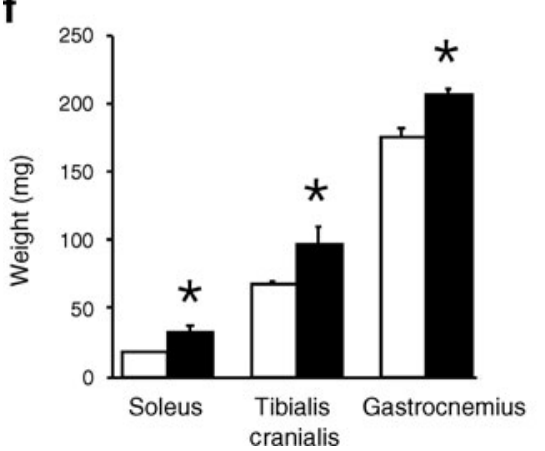

C

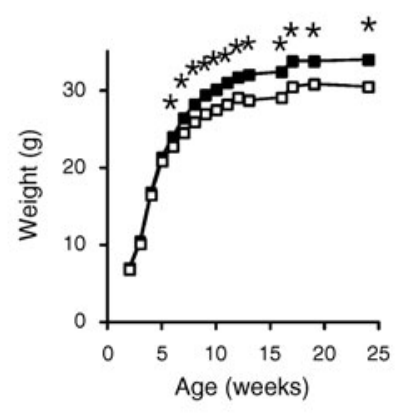

g

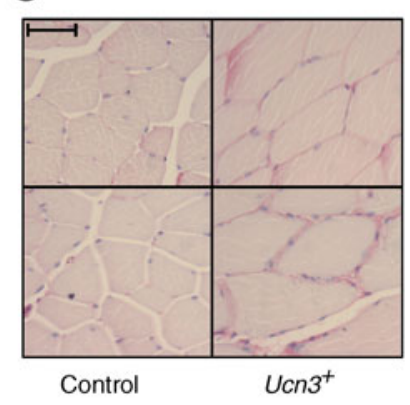

d

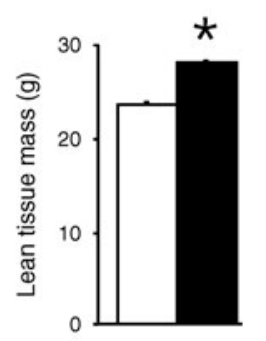

e

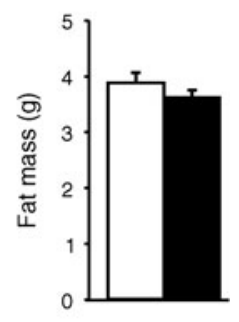

h

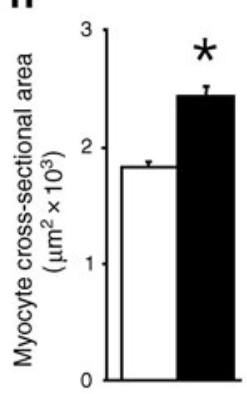

i

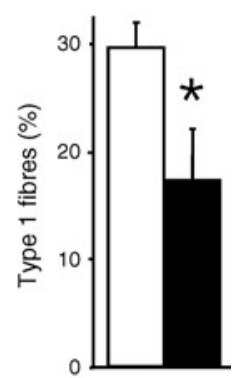

Fig. $1 U c n 3$ overexpression in tissues of $\mathrm{Ucn}^{+}$transgenic mice results in increased skeletal muscle mass with myocyte hypertrophy. a A construct for overexpression of $U c n 3$ was designed as shown, putting the transgene under the control of the mouse Rosa 26 promoter. The position of primers used to genotype mice is shown. b Northern blots of RNA extracted from tissues of $\mathrm{Ucn}^{+}$mice and control littermates probed with Ucn3 and S16 cDNA. B, brain; H, heart; L, liver; K, kidney; M, muscle. c Growth curves of $U c n 3^{+}$mice (black squares) show they are heavier than controls (white squares) from 6 weeks of age $(n=17-19)$. Whole body composition analysis showed this to be due to (d) increased lean tissue mass with (e) no change in fat mass $(n=10)$. $\mathbf{f}$ Weight of individual skeletal muscles showing that $U c n 3^{+}$mice have increased skeletal muscle mass $(n=13-17)$. g Muscle histology $(\times 200$ magnification, scale bar $50 \mu \mathrm{m})$ and (h) myocyte cross-sectional area reveal increased muscle mass to be due to myocyte hypertrophy $(n=4)$. i Muscle fibre type distribution in the soleus muscle. Extensor digitorum longus and gastrocnemius muscles were $>98 \%$ type 2 in control and $U c n 3^{+}$mice (not shown). ${ }^{*} p<0.05$ vs control. d-i Black bars, $U c n 3^{+}$; white bars, control
Experiments were carried out on male mice between 16 and 26 weeks old. $U c n 3^{+}$mice were heterozygous for the transgene and controls were transgene-negative littermates. Principles of laboratory animal care (NIH No. 85-23, 1985) were followed. All procedures were approved by The Salk Institute Animal Use and Care Committee or carried out according to the UK Animals Scientific Procedures Act, 1986. Food intake was measured over 6 days in individually housed mice and the average intake per day was adjusted for body weight as per Kleiber's allometric law.

In vivo studies Procedures were carried out in the morning. 'Fed' is defined as food not withheld, 'fasted' is defined as $18 \mathrm{~h}$ food deprivation. Measurements were carried out fed except where stated, with the exception of glucose tolerance tests (GTTs) and insulin tolerance tests (ITTs), which were carried out following 6 or $3 \mathrm{~h}$ food deprivation, respectively. Glucose $(2 \mathrm{~g} / \mathrm{kg})$ or insulin (0.75 IU/kg) was administered i.p. in saline and tail blood collected for immediate glucose measurement (Lifescan OneTouch Ultra glucometer; Johnson \& Johnson, Milpitas, CA, USA). For insulin measurements, blood was collected by retro-orbital bleed. For other measurements, blood and tissues were collected immediately after animals had been killed. For glucagon response test and insulin signalling studies, see Electronic supplementary material (ESM), Methods.

High-fat feeding Mice were fed an HFD (45\% energy as fat) or control low-fat diet (LFD) (10\% energy as fat) (products D12451 and D12450B, respectively; Research Diets, New Brunswick, NJ, USA) from weaning (3 weeks) until 16 weeks old and weighed weekly. Food intake was quantified at 15 weeks. GTT, ITT and time course measurement of blood glucose levels during fasting were performed, and pre- and post-fasting weight recorded. Mice were culled fasted or fed, and individual fat depots and hindlimb muscles were dissected out and weighed. 
Metabolism cage studies Rates of oxygen uptake $\left(\dot{V} \mathrm{O}_{2}\right)$, rates of carbon dioxide production $\left(\dot{V} \mathrm{CO}_{2}\right)$, food intake and locomotor activity (ESM Methods) were measured continuously and simultaneously over 3 days (LabMaster; TSE-Systems, Bad Homburg, Germany) after 48 h adaptation in singly housed mice.

Body composition analysis Body composition of whole carcasses was determined using PIXImus densitometry (GE-Lunar, Madison, WI, USA) as previously validated [16].

Histology Liver and quadriceps muscles were formalinfixed, dehydrated in graded ethanol/xylene, paraffinembedded, sectioned at $5 \mathrm{~mm}$ intervals and stained with haematoxylin and eosin. Liver was stained with periodic acid-Schiff's reagent (PAS) with and without diastase pre-treatment. For measurement of myocyte size, hindquarters were skinned and fixed, and decalcified in $10 \%$ (wt/vol.) formaldehyde, $8 \%$ (wt/vol.) formic acid and $1 \%$ (vol./vol.) methanol with the legs in mild flexion for $48 \mathrm{~h}$. Transverse sections through the mid-femur were paraffinembedded, sectioned at $4 \mathrm{~mm}$ intervals and stained with PAS. Areas of 20 myocytes/mouse were measured from $\times 300$ digital images of rectus femoris muscle in crosssection using imaging software (QCapture Pro; QImaging, Surrey, BC, Canada).

Muscle fibre typing Tissues were dissected and snap-frozen in liquid nitrogen-cooled melting isopentane. Transverse sections $(8 \mu \mathrm{m})$ were stained with myosin ATPase to demonstrate fibre types classified as type 1 or type 2 as previously described [17]. Digital images $(100 \times)$ covering the whole section and including, when possible, a minimum of 350 fibres, were analysed to quantify fibre type distribution using Image-Pro Plus software (Media Cybernetics, Bethesda, MD, USA).

Hormone measurements Insulin and IGF-1 were measured using Sensitive Rat Insulin RIA (Linco Research, St Charles, MO, USA) and Mouse/Rat IGF-1 Quantikine ELISA (R\&D Systems, Minneapolis, MN USA) kits, respectively. For corticosterone, glucagon and growth hormone measurements, see ESM Methods.

Combined GTT and $\left[^{3} H\right] g l u c o s e$ or 2-deoxy $\left[^{3} H\right]$ glucose tracer uptake into tissues This was carried out based on methods previously described $[18,19]$. Mice were fasted for $3 \mathrm{~h}$ and weighed. After tracer $\left(3.7 \mathrm{MBq} / \mathrm{mlD}-\left[3-{ }^{3} \mathrm{H}\right]\right.$ glucose or $1.9 \mathrm{MBq} / \mathrm{ml}$ 2-deoxy-D-[2,6- $\left.{ }^{3} \mathrm{H}\right]$ glucose solution [Amersham Pharmacia Biotech, Little Chalfont, UK]) with $2 \mathrm{~g} / \mathrm{kg}$ glucose in $0.3 \mathrm{ml}$ saline had been injected, blood glucose and plasma radioactivity were measured over
90 min and AUC calculated. At 90 min, mice were killed, and tissues dissected and snap-frozen. To estimate glucose uptake, tissues were homogenised in distilled $\mathrm{H}_{2} \mathrm{O}$ and centrifuged for $10 \mathrm{~min}$ at $600 \mathrm{~g}$ and $4{ }^{\circ} \mathrm{C}$. Total $\left[{ }^{3} \mathrm{H}\right]$ glucose and $\left[{ }^{3} \mathrm{H}\right]$ glucose 6-phosphate were counted in the supernatant fraction after separation using a 100 to 200 mesh anion exchange resin column (AG1-X8; Bio-Rad, Hercules, CA, USA). Blood radioactivity AUC and $\left[{ }^{3} \mathrm{H}\right]$ glucose uptake were used to calculate glucose clearance into each tissue. Total tissue glycogen was estimated as previously described [20]. For glucose incorporation into glycogen, radioactivity of digested samples was divided by the specific activity in serum over the GTT time course. For 2-deoxyglucose uptake, weighed tissues were digested at $50^{\circ} \mathrm{C}$ overnight in $1 \mathrm{ml}$ Soluene-350 (Packard Bioscience, Groningen, the Netherlands). Uptake was calculated from the plasma profiles of 2-deoxy $\left[{ }^{3} \mathrm{H}\right]$ glucose and glucose, together with concentrations of radiolabelled tracer in tissue.

Hyperinsulinaemic clamps Mice were implanted with an indwelling jugular catheter 3 days prior to experiments. Fasted mice received a $2 \mathrm{~h}$ basal saline infusion, then a primed continuous infusion of short-acting insulin consisting of a bolus of $100 \mathrm{mU} / \mathrm{kg}$ for $3 \mathrm{~min}$, followed by a constant rate of $2.5 \mathrm{mU} \mathrm{kg}^{-1} \mathrm{~min}^{-1}$ (a standard protocol designed to achieve a high physiological insulin level of $\sim 450 \mathrm{pmol} / 1$ [21]). Glucose $(20 \% \mathrm{wt} / \mathrm{vol}$. in saline) was infused at a variable rate $(2.5-12 \mu \mathrm{l} / \mathrm{min})$ to maintain euglycaemia $(6-7 \mathrm{mmol} / \mathrm{l})$ as far as possible. Tail blood samples were used to monitor glycaemia at baseline (0), and at 20, 40, 60, 70, 80, 90, 100, 110 and $120 \mathrm{~min}$.

Phosphoenolpyruvate carboxykinase 1 activity This was assayed in liver homogenates as previously described [22].

Northern blotting Total RNA was extracted from tissues and northern blotting carried out as previously described [23] using deoxycytidine $5^{\prime}-\left[{ }^{32} \mathrm{P}\right]$ triphosphate-labelled mouse Ucn3 cDNA. Blots were rehybridised with S16 probes to control for loading.

Tissue lysates, SDS-PAGE and immunoblotting Protein abundance and phosphorylation in tissue lysates was quantified by SDS-PAGE as previously described [19]. Primary antibodies were from Cell Signaling Technology (Beverley, MA, USA), except pY612-IRS-1 (BioSource International, Camarillo, CA, USA), total IRS-1 (Upstate Cell Signaling Solutions, Waltham, MA, USA), myostatin (Millipore, Watford, UK) and tubulin (Li-COR Biosciences, Lincoln, NE, USA). Primary antibodies against phosphorylated proteins were used at 1:500 dilution, those against tubulin at 1:10,000 and all other primary antibodies at 1:1,000. For AMPK, see ESM methods. 
Quantitative real-time PCR Total RNA was extracted from tissues and $500 \mathrm{ng}$ reverse-transcribed to cDNA using a kit (QuantiTect DNase; Qiagen, Crawley, UK). PCR cycling was carried out using a LightCycler480 (Roche Diagnostics, Mannheim, Germany). Standard curves were constructed for each assay using serial dilution of cDNA pooled from all samples. Reactions were performed in triplicate. Results were corrected for 18S, cyclophilin A and Hprt1 (also known as $H p r t)$ mRNA expression levels, which were not different between groups. For cyclophilin A, Ppargcla, Ucn2 and Ucn3, assays Mn02342429-g1, Mm00440939-m1, Mm01227928-s1 and Mm00453206-s1 (Applied Biosystems, Carlsbad, CA, USA) were employed. Other gene-specific assays and probes were designed using the Universal ProbeLibrary Assay Design Center (Roche). Polymerase, buffer and dNTPs were provided from the LightCycler480 Probes Master kit (Roche). Details of primer sequences and probes are available upon request.

Statistical analysis Statistical analyses employed the Student's two-tailed $t$ test, or one- or two-way ANOVA with post hoc analysis using Bonferroni's or Dunnett's test as appropriate. Data are presented as mean $\pm \mathrm{SEM}$. Differences were considered statistically significant at $p<0.05$. For further details, see ESM, Methods.

\section{Results}

Generation of transgenic mice overexpressing Ucn3 Ucn $3^{+}$ mice were generated by placing the coding region of mouse Ucn 3 under the control of the ubiquitously expressed Rosa26 promoter (Fig. 1a). Progeny from founders were screened and a line selected that expressed Ucn 3 mRNA at high levels in a wide range of organs, as reflected in elevated plasma and tissue peptide levels (Fig. $1 \mathrm{~b}$ and Table 1). Mice carrying the transgene were born at the expected Mendelian ratio and showed no

Table 1 Urocortin 3-like immunoreactivity in tissues of control and $U c n 3^{+}$mice

\begin{tabular}{llc}
\hline Tissue & Control $(\mathrm{pg} / \mathrm{g})$ & $U_{c n} 3^{+}(\mathrm{pg} / \mathrm{g})$ \\
\hline Brain & $257 \pm 29$ & $11,308 \pm 475$ \\
Heart & $\mathrm{ND}$ & $597 \pm 54$ \\
Liver & $105 \pm 12$ & $576 \pm 38$ \\
Pancreas & $550 \pm 135$ & $1,627 \pm 231$ \\
Plasma & $52 \pm 5$ & $171 \pm 21$ \\
\hline
\end{tabular}

Data are mean \pm SEM, $n=3$

ND, not detectable obvious signs of ill health until at least 18 months old or any significant pathology on routine post-mortem examination (not shown).

$\mathrm{Ucn}^{+}$mice have increased skeletal muscle mass $\mathrm{Ucn}^{+}$ mice were heavier than wild-type littermates by 6 weeks old. By 12 weeks this difference stabilised with $U c n 3^{+}$ mice weighing $\sim 12 \%$ more than controls (Fig. 1c). Carcass analysis revealed that this was entirely due to increased lean tissue mass (Fig. 1d, e). Weights of parenchymal organs, femoral length and nose to tail length were not significantly different between genotypes (not shown). Individual skeletal muscle weights (whether predominantly type 1, type 2 or mixed fibre type) were greater in $U c n 3^{+}$mice (Fig. 1f), whereas fat pad weights were unaltered (ESM Fig. 1). Histology revealed muscle hypertrophy with increased myofibre diameter (Fig. 1g, h), and a shift towards type 2 glycolytic muscle fibre type (Fig. 1i).

$U \mathrm{Cn} 3^{+}$mice have an increased energy requirement Food intake was significantly greater in $U c n 3^{+}$mice, even when adjusted for body weight, signifying an increased energy requirement (Fig. 2a). $\dot{V} \mathrm{O}_{2}$ and $\dot{V} \mathrm{CO}_{2}$ were $\sim 7 \%$ higher in $\mathrm{Ucn}^{+}$mice (Fig. 2b, c), but individual variation did not allow conclusions to be drawn on the significance of this. Increased respiratory exchange ratio (RER) indicated higher proportional use of carbohydrate as a metabolic fuel source (Fig. 2d). While voluntary running wheel activity was not different, $U c n 3^{+}$mice showed increased spontaneous activity in metabolism cages (ESM Fig. 1). This may in part account for their increased energy requirements, but cannot explain other aspects of their phenotype including glucose metabolism as described below.

$\mathrm{Ucn}^{+}$mice show more rapid falls in blood glucose during fasting and a GTT Ucn $3^{+}$mice had lower fed blood glucose levels, a more rapid drop in glucose at the onset of fasting and significantly lower glucose levels during fasting (Fig. 2e). $U c n 3^{+}$mice showed improved glucose tolerance across a GTT (Fig. 2f). To determine whether the effects of $U c n 3^{+}$were mediated, as anticipated, by CRFR2, $\mathrm{Ucn}^{+}{ }^{+}$mice were crossed with $\mathrm{Crfr}$ 2-null mice. Importantly, the body mass increase, and fasting and GTT glucose-lowering effects of the $\mathrm{Ucn}^{+}$transgene were negated by the $C r f r 2$-null mutation, confirming that muscle hypertrophy and glucose phenotype were dependent on CRFR2 (Fig. 2g-i). Ucn $3^{+}$mice had increased uptake of 2deoxy $\left[{ }^{3} \mathrm{H}\right]$ glucose to tissues per unit mass, particularly skeletal muscle, during a GTT (Fig. 2j), demonstrating that their accelerated disposal of a glucose load was not due to increased muscle mass alone. Ucn $3^{+}$muscle showed increased glycogen storage and incorporation of $\left[{ }^{3} \mathrm{H}\right]$ glucose into glycogen during the GTT (Fig. 2k, 1). 
Fig. $2 \mathrm{Ucn}^{+}$mice have an increased energy requirement and uptake of glucose to tissues. a Food intake is higher in $\mathrm{Ucn}^{+}$mice (black bars) than controls (white bars) $(n=10-11) . \mathbf{b} \dot{V} \mathrm{CO}_{2}$, (c) $\dot{V} \mathrm{O}_{2}$ and (d) RER are elevated in $U c n 3^{+}$mice $(n=5-7)$. e Blood glucose levels during fasting $(n=10-12)$ and (f) during GTT $(n=10)$ showed lower glucose in $\mathrm{Ucn}^{+}{ }^{+}$mice (black squares) than in controls (white squares). g Body weight, (h) fasting blood glucose and

(i) GTT in $U c n 3^{+}$mice on a Crfr2-null background ( $n=5-6)$ show that these aspects of phenotype are mediated via CRFR2. Light grey bars and circles, Crfr2-null; dark grey bars and circles, Crfr2-null/ $U c n 3^{+}$. j Glucose uptake to peripheral tissues, and (k) total glycogen and (l) acute incorporation of glucose into glycogen in skeletal muscle were increased in $U c n 3^{+}$mice in a GTT $(n=8)$. m Phosphorylation of glycogen synthase at Ser641 indicated increased enzyme activity $(n=7) .{ }^{*} p<0.05$ vs control and ${ }^{\dagger} p<0.05$ for $C r f r 2$-knockout vs control; ${ }^{\star} p=0.07$ for $U c n 3^{+}$ vs control
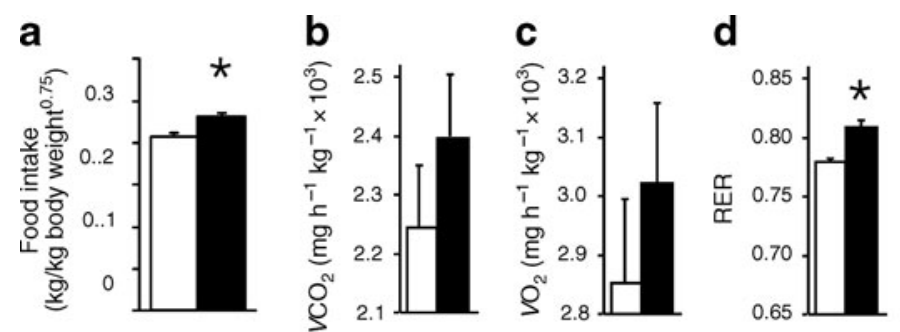

e

\section{f}

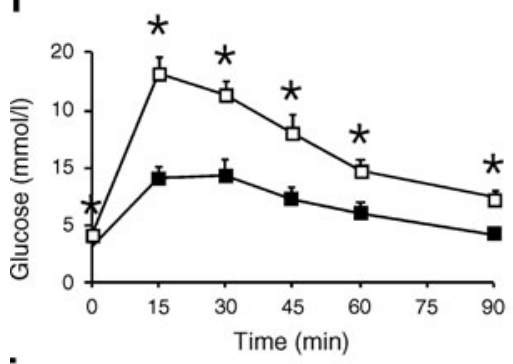

g
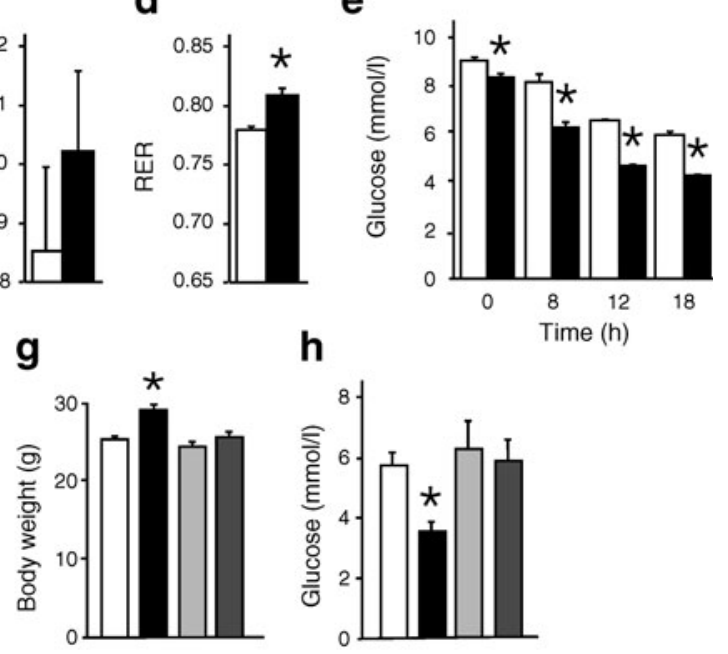

j
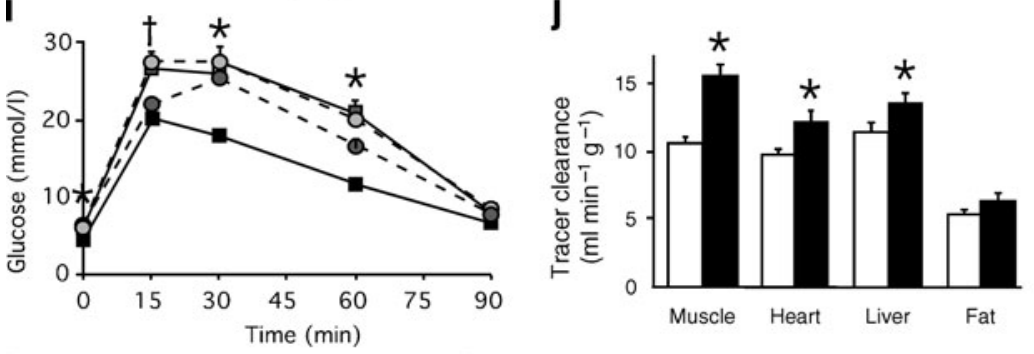

k

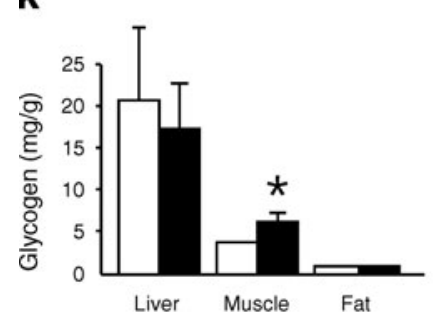

I

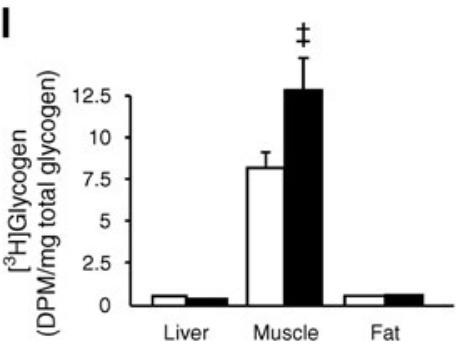

m

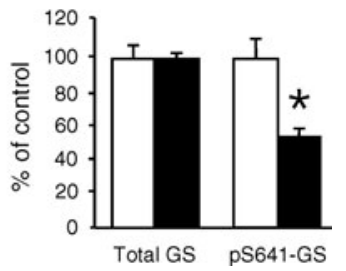

Decreased phosphorylation of glycogen synthase at residue S641 indicated increased glycogen synthase activity (Fig. 2m).

$\mathrm{Ucn}^{+}{ }^{+}$mice exhibit adequate counter-regulatory responses upon fasting Since lower blood glucose levels were consistently found in fed and fasted $U c n 3^{+}$mice (Fig. 2e), we examined their counter-regulatory responses. Following fasting, circulating corticosterone and glucagon levels in $U c n 3^{+}$mice, as well as glucose production in response to glucagon administration to fed mice, were the same as in controls (ESM Fig. 2). Moreover, in $\mathrm{Ucn}^{+}$mice, fasting insulin was lower than in controls, showing appropriate downregulation in response to hypoglycaemia (Fig. 3a). $\mathrm{Ucn}^{+}$mice lost a greater proportion of liver weight (a measure of glycogen mobilisation and depletion) and showed less hepatic glycogen staining after fasting (Fig. 3b, c). Pepck (also known as Pckl) mRNA expression was upregulated appropriately in $U c n 3^{+}$mice after fasting (Fig. 3d) and phosphoenolpyruvate carboxykinase 1 (PEPCK) enzyme activity levels were increased when fed and fasted, consistent with gluconeogenesis being active at all times (Fig. 3e).

$\mathrm{Ucn}^{+}$mice have normal insulin sensitivity Lower fasting insulin/glucose ratio indicated the possibility of increased insulin sensitivity in $\mathrm{Ucn}^{+}$mice (Fig. 4a). However, during an ITT there was no difference in the magnitude of response to insulin, implying no difference in insulin sensitivity (Fig. 4b). Moreover, basal (fed) activating phosphorylation of the key signalling intermediates, Akt and IRS-1, in skeletal muscle and liver was decreased in $U_{c n} 3^{+}$mice, presumably due to their lower insulin levels (Fig. 4c). While exogenous insulin caused the expected increase in IRS-1 and Akt phosphorylation, there were no differences between genotypes (ESM Fig. 2), again 
Fig. $3 \mathrm{Ucn}^{+}$mice have an adequate counter-regulatory response to fasting. a Fasting insulin downregulation $(n=9$ 12) in $\mathrm{Ucn}^{+}$mice is appropriate for blood glucose levels. b Decrease in liver weight (indicative of glycogen mobilisation) following fasting $(n=6-12)$ is increased in $\mathrm{Ucn}^{+}{ }^{+}$mice. c PAS staining showed relative depletion of glycogen in the periportal area of $\mathrm{Ucn}^{+}$livers compared with controls $(\times 4$ magnification scale bar $500 \mu \mathrm{m} ; \times 10$ magnification scale bar $200 \mu \mathrm{m})$. d Pepck mRNA and (e) PEPCK activity in fed and fasted $\mathrm{Ucn}^{+}$ mice $(n=6-8)$. a, b, d, e Black bars, Ucn $3^{+}$; white bars, control. ${ }^{*} p<0.05$ for $U c n 3^{+}$vs control a
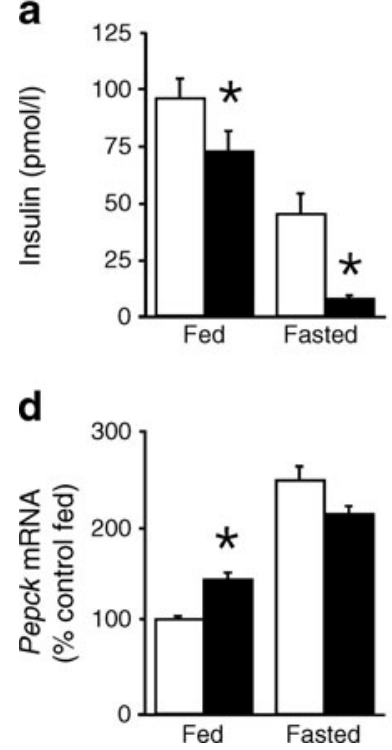

b

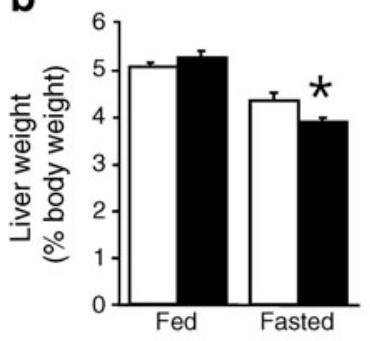

C

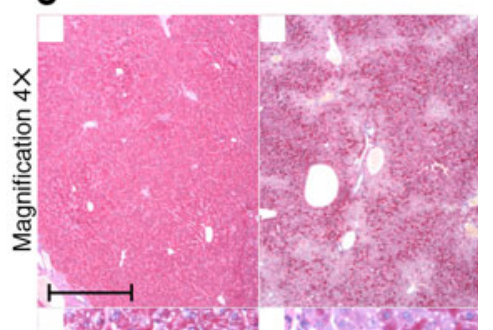

e
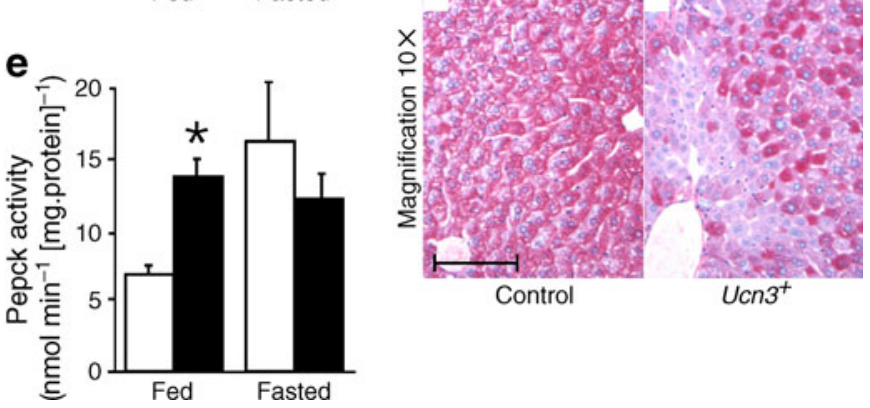

a

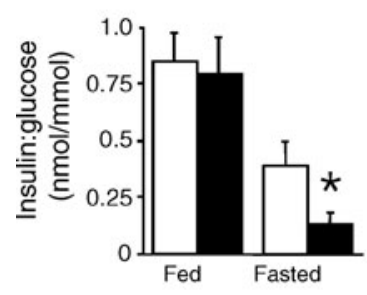

b

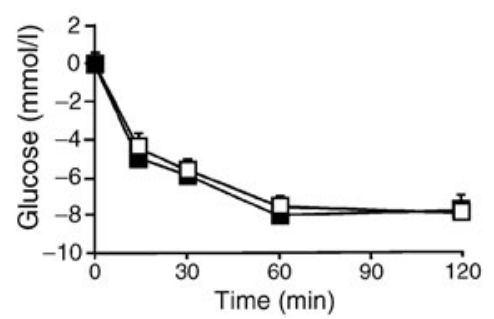

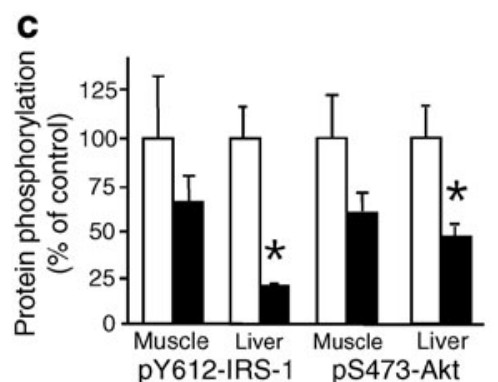

d
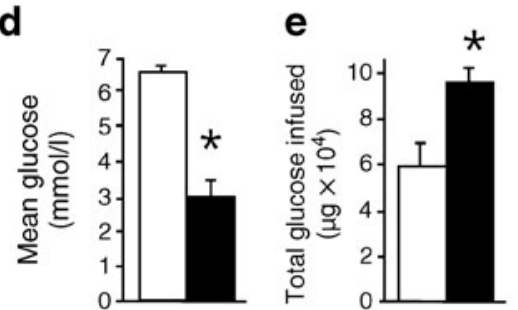

h

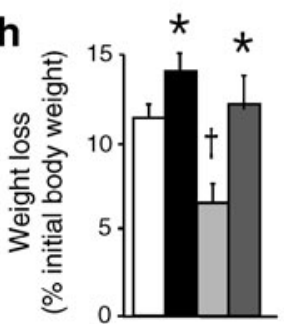

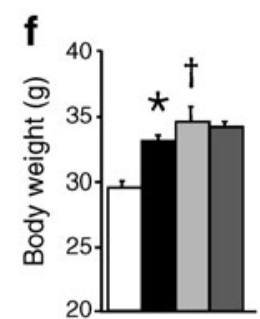

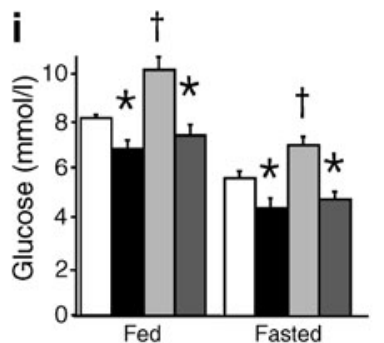

j
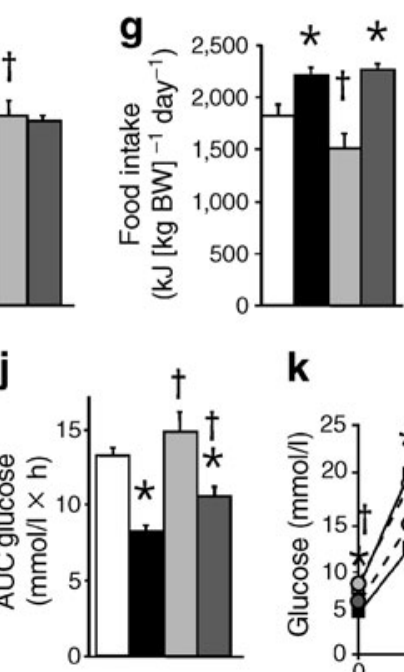

$\mathbf{k}$

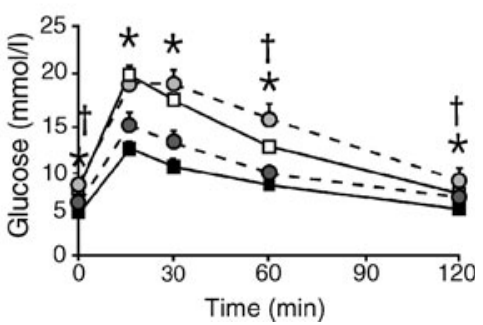

glucose level and (e) total glucose infused from $70-120 \mathrm{~min}$ in a glucose clamp $(n=5)$. f Body weight and (g) energy intake in $\mathrm{kJ}$ per $100 \mathrm{~g}$ body weight (BW) at 16 weeks of age. $\mathbf{h}$ Weight loss and (i) blood glucose levels following fasting, with (j) AUC glucose and (k) blood glucose levels during a GTT in mice fed LFD or HFD $(n=13-17)$. ${ }^{*} p<0.05$ vs control and ${ }^{\dagger} p<0.05$ vs LFD. f-k White, control LFD; black, $U c n 3^{+}$LFD; light grey, control HFD; dark grey, Ucn $3^{+}$HFD 
indicating no increase in insulin sensitivity. Total levels of IRS-1 and Akt did not differ with genotype (not shown). p70 S6 kinase (p70S6) phosphorylation as a measure of Akt-mechanistic target of rapamycin (mTOR)-p70S6 signalling pathway activation was not different from controls under basal conditions (ESM Fig. 2). Finally, euglycaemic-hyperinsulinaemic clamps demonstrated increased glucose uptake in $\mathrm{Ucn}^{+}$mice at a fixed insulin dose (Fig. 4e). However, euglycaemia could not be achieved even at maximal glucose infusion rates in $\mathrm{Ucn}^{+}$mice at this standard high physiological insulin dose ( $450 \mathrm{pmol} / 1$ [21]), whereas euglycaemia was achieved in controls (Fig. 4d). This technique relies on the assumption that non-insulin-dependent glucose uptake is the same between experimental groups, but our in vivo data suggest that this was not the case in $U c n 3^{+}$mice. Hence further comparisons using this standard method for measuring insulin sensitivity were not attempted.

$\mathrm{Ucn}^{+}$mice resist adiposity and hyperglycaemia on $H F D$ On control LFD from weaning to 16 weeks, $U c n 3^{+}$ mice were heavier than controls, as seen in animals on normal chow. However, while controls gained weight despite reducing their energy intake on HFD, $U c n 3^{+}$mice resisted weight gain while maintaining their energy intake (Fig. 4f, g). Moreover, LFD-fed $\mathrm{Ucn}^{+}{ }^{+}$mice lost a greater proportion of body weight following fasting, implying increased mobilisation of energy stores, a process that was not attenuated by HFD as in controls (Fig. 4h). $U c n 3^{+}$mice resisted the increase in fat mass on HFD (Table 2). Ucn $3^{+}$ mice had lower fasting blood glucose than controls and resisted HFD-induced hyperglycaemia, showing lower glucose on both diets (Fig. 4i-k). In an ITT, there was no significant difference in the initial decrement between genotypes and therefore again no evidence of increased insulin sensitivity in $\mathrm{Ucn}^{+}$mice (ESM Fig. 2).

Mechanism for metabolic phenotype and muscular hypertrophy Ucn2 (the endogenous urocortin in muscle) and $C r f r 2$ mRNA expression were unchanged in $U_{c n} 3^{+}$ skeletal muscle (ESM Fig. 3). To further characterise the metabolic pathways involved in the phenotype of $U c n 3^{+}$ mice, candidate gene expression was examined in skeletal muscle and liver. AMPK may improve glucose homeostasis [24], but its activity and mRNA expression were not altered in $\mathrm{Ccn}^{+}$muscle or liver (Table 3, ESM Fig. 3). Glut1 (also known as Slc2a1) and Glut4 (also known as Slc2a4) expression was also unchanged in $U c n 3^{+}$mice (Table 3, ESM Fig. 3). However, Ucp2 and Ucp3 mRNA was upregulated in muscle (Fig. 5a), suggesting the possibility of increased metabolic uncoupling or fatty acid metabolism. Cpt1a mRNA was greatly upregulated in liver (Fig. 5b), consistent with increased hepatic fat oxidation. mRNA levels of other metabolic genes were examined under conditions of HFD and LFD, and when fed or fasted (Table 3). While these experimental conditions regulated gene expression as expected, no effect of genotype was observed.

Myostatin mRNA levels were unchanged in $U c n 3^{+}$muscle. However, myostatin propeptide levels were decreased (Fig. 5c, d). Intriguingly, Igfl expression was upregulated $\sim 80 \%$ in $\mathrm{Ucn}^{+}{ }^{+}$skeletal muscle, but unchanged in liver (Fig. 5e, f). In contrast, serum levels of IGF-1 were only marginally increased (16\%) (Fig. 5g). Circulating growth hormone levels were unchanged in $\mathrm{Ucn}^{+}$mice (ESM Fig. 3), thus indicating that CRFR2 may stimulate IGF-1 in muscle via a paracrine action that causes muscle hypertrophy and also stimulates glucose uptake independently of the growth hormone-IGF-1 axis.

\section{Discussion}

The model of chronic urocortin 3 overabundance presented here shows a novel metabolic phenotype, with lean body composition, increased skeletal muscle mass, increased disposal and use of glucose in muscle, and increased energy intake with reduced adiposity on an HFD. Strikingly, $U c n 3^{+}$mice have lower blood glucose levels and
Table 2 Adiposity of control and $U c n 3^{+}$mice fed LFD or HFD

\footnotetext{
Data are mean \pm SEM, $n=6-9$

${ }^{a} p<0.05$ vs control;

${ }^{\mathrm{b}} p<0.05$ vs LFD

$\mathrm{BW}$, body weight
}

\begin{tabular}{lcccc}
\hline Fat pads & Control $(\mathrm{mg})$ & $\operatorname{Ucn}^{+}(\mathrm{mg})$ & Control $(\mathrm{mg} / \mathrm{g} \mathrm{BW})$ & Ucn3 $^{+}(\mathrm{mg} / \mathrm{g} \mathrm{BW})$ \\
\hline LFD & & & & \\
Epididymal & $734 \pm 70$ & $603 \pm 50$ & $22.9 \pm 2.4$ & $17.0 \pm 0.5^{\mathrm{a}}$ \\
Mesenteric & $363 \pm 27$ & $353 \pm 15$ & $11.2 \pm 0.6$ & $10.0 \pm 0.3^{\mathrm{a}}$ \\
Inguinal & $530 \pm 48$ & $438 \pm 30$ & $16.5 \pm 0.6$ & $12.3 \pm 0.6^{\mathrm{a}}$ \\
HFD & & & & \\
Epididymal & $1,123 \pm 99^{\mathrm{b}}$ & $803 \pm 106^{\mathrm{a}}$ & $31.0 \pm 2.6^{\mathrm{b}}$ & $23.1 \pm 2.8$ \\
Mesenteric & $486 \pm 65$ & $320 \pm 22^{\mathrm{a}}$ & $13.1 \pm 0.9$ & $9.3 \pm 0.6^{\mathrm{a}}$ \\
Inguinal & $909 \pm 145^{\mathrm{b}}$ & $482 \pm 23^{\mathrm{a}}$ & $24.3 \pm 2.5^{\mathrm{b}}$ & $14.0 \pm 0.5^{\mathrm{a}}$ \\
\hline
\end{tabular}


Table 3 Genes not altered in $U c n 3^{+}$mice compared with controls

\begin{tabular}{lll}
\hline mRNA & Tissue & Function \\
\hline Glut4 & Muscle & Glucose transport \\
Hk2 & Muscle & Glucose transport \\
Pdha1 & Muscle & Glycolysis/TCA cycle \\
Cs & Muscle & TCA cycle \\
Prkaa2 & Muscle & Fat and glucose catabolism \\
Cpt1b & Muscle & Lipid oxidation \\
Acsl1 & Muscle & Fatty acid metabolism \\
Lpl & Muscle & Fatty acid metabolism \\
Ppargc1a & Muscle & Mitochondrial metabolism \\
Fasn & Muscle, liver & Lipogenesis \\
Ppara & Muscle, liver & Control of fat oxidation \\
Ppard & Muscle, liver & Control of fat oxidation \\
Srebf1 & Liver & Lipogenesis \\
Gpam & Liver & Esterification \\
Acaca & Liver & Substrate switching \\
Pdk4 & Liver & Substrate switching \\
G6pc3 & Liver & Gluconeogenesis \\
Ucp1 & BAT, WAT & Mitochondrial uncoupling \\
\hline
\end{tabular}

BAT, brown adipose tissue; TCA, tricarboxylic acid; WAT, white adipose tissue

increased energy intake even under basal conditions, which Crfr2-, Ucn2- and Ucn3-knockout models do not exhibit until challenged with HFD or aged. Interestingly, $U c n 3^{+}$ mice do not show increased insulin sensitivity, suggesting that augmented glucose uptake occurs largely independently of insulin action. This again contrasts with the knockout mice, all of which exhibit increased insulin sensitivity, albeit via different mechanisms [9-11, 14]. Accordingly, the metabolic alterations in $U \mathrm{cn} 3^{+}$mice appear to be primarily in carbohydrate metabolism, with accelerated glucose uptake and metabolism by muscle, and increased RER reflecting greater proportional carbohydrate use [25].

An AMPK-dependent role for CRFR2 in stimulating thermogenesis in skeletal muscle has been described [13], suggesting a possible mechanism by which glucose uptake to muscle may be enhanced in $U c n 3^{+}$mice. However, we did not find evidence for increased AMPK activity, but did observe upregulation of uncoupling proteins (UCP) 2 and 3. These mitochondrial proteins are normally produced in skeletal muscle, where their physiological functions are highly controversial $[26,27]$. UCP3 has been proposed to facilitate fatty acid translocation and oxidation, and to mitigate reactive oxygen species production. Its primary role is not generally considered to be thermogenesis, but it does have the capacity to stimulate heat production and glucose oxidation in vivo, all roles compatible with the phenotype of $\mathrm{Ucn}^{+}$mice. UCP2 is even less well understood, but is generally proposed to fulfil similar functions. Increased UCP activity, as observed in transgenic mice, will result in increased mitochondrial oxidative phosphorylation and glucose metabolism and thus uptake, as well as increased fatty acid metabolism [28, 29]. Conversely, enhanced glucose transport achieved by overabundance of GLUT4 results in increased UCP production and activity in skeletal muscle, which in turn raises glucose use and lowers blood glucose [30]. This is plausibly the effective mechanism in $\mathrm{Ucn}^{+}$mice, with the increase in glucose metabolism responsible for protection against the diet-induced obesity seen in control mice.

Transgenic mouse models of increased UCP gene expression or increased metabolic rate normally exhibit decreased body weight due to lean body composition,
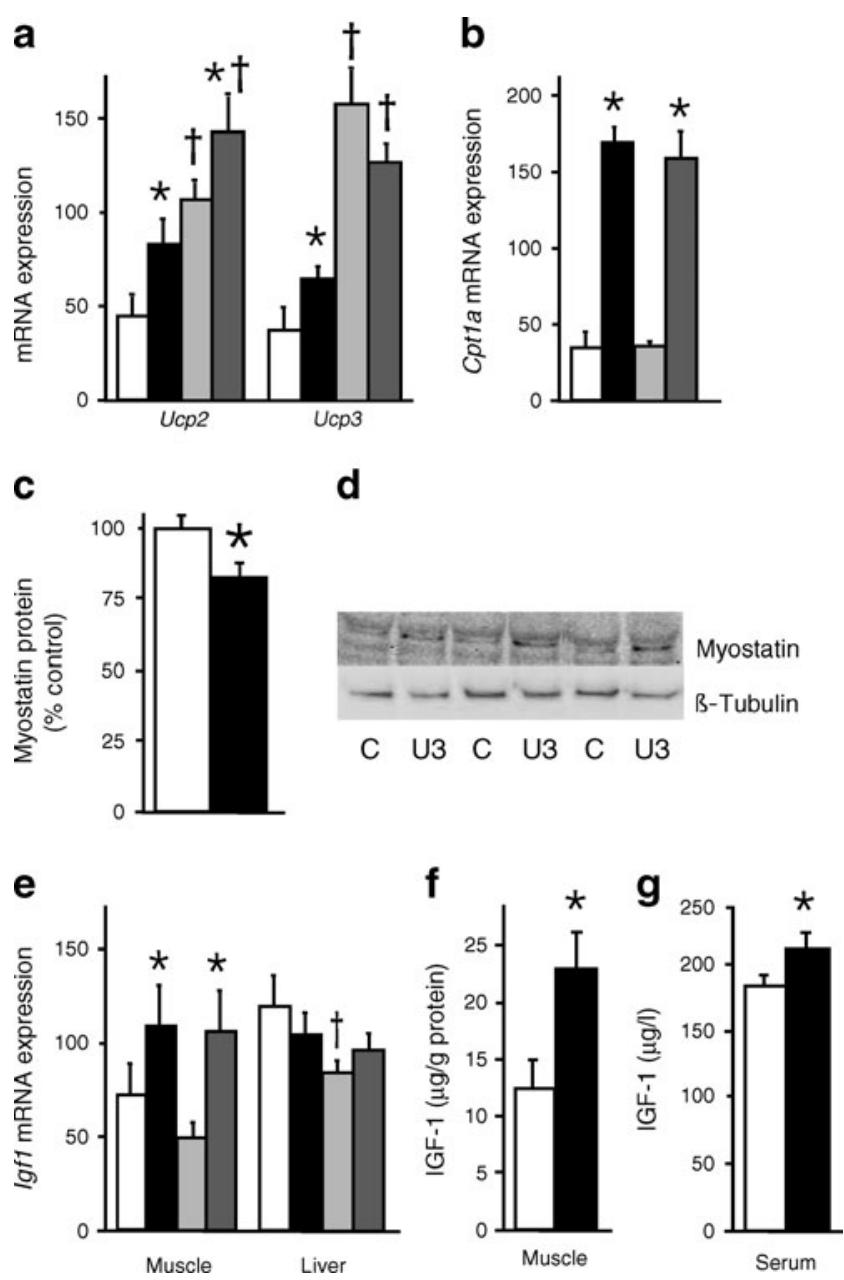

Fig. 5 a $U c p 2$ and $U c p 3$ mRNA in muscle $(n=11-15)$. b Cpt1 a mRNA in liver $(n=6-8)$. c Quantification of myostatin protein levels in (d) western blot $\left(\mathrm{C}\right.$, control; $\left.\mathrm{U} 3, U_{c n} 3^{+}\right)(n=11)$. e Igf1 mRNA $(n=11-15)$, and (f) IGF-1 protein in muscle and (g) IGF-1 plasma levels $(n=11)$. mRNA levels $(\mathbf{a}, \mathbf{b}, \mathbf{e})$ are expressed as percentage of the average value of all samples. ${ }^{*} p<0.05$ vs control and ${ }^{\dagger} p<0.05$ vs fed. White, control fed; black, $U c n 3^{+}$fed; light grey, control fasted; dark grey, $U c n 3^{+}$fasted 
whereas a notable feature of $U c n 3^{+}$mice is their increased body weight, entirely due to increased muscle mass. This muscular hypertrophy helps explain their metabolic phenotype. Increased IGF-1 abundance in $U c n 3^{+}$skeletal muscle provides a plausible link between the muscular and metabolic phenotypes of the mice. Decreased myostatin expression may also contribute to muscle hypertrophy; indeed, myostatin-null mice show similar fasting glucose and body composition responses to HFD as do $\mathrm{Ucn}^{+}$mice [31]. However, myostatin is quantitatively much less affected than IGF-1 in $U c n 3^{+}$mice.

In addition to its anabolic effects, IGF-1 has long been known to exert metabolic effects similar to insulin, with increased glucose uptake and glycogen synthesis, and hypoglycaemia as seen in $U c n 3^{+}$mice $[32,33]$. These effects are mediated via the IGF-1 receptor in skeletal muscle [34]. Overabundance of IGF-1 in muscle can cause a shift towards glycolytic metabolism [35], which may improve body composition and insulin sensitivity [36]. Thus IGF-1 may be responsible for the observed shift towards type 2 muscle fibres in $U c n 3^{+}$mice. Transgenic or pharmacological models of increased IGF-1 levels show evidence of increased flux through various signalling pathways including the phosphatidylinositol 3-kinase pathway in tissues [37, 38], whereas decreased IRS-1 and Akt phosphorylation was seen in tissues from $\mathrm{Ucn}^{+}$mice following fasting. This may be because the observed increase in IGF-1 production, and hence presumably action, is of a lesser magnitude to that seen in these other models, and the IGF-1 axis in $U c n 3^{+}$mice will still be subject to regulation by endogenous factors including feeding status. Likewise, no difference in Akt-mTOR-p70S6 protein synthesis pathway signalling was observed in $U c n 3^{+}$mice under basal conditions when adaptation of signalling activity might have been expected. Detailed dynamic signalling pathway studies under conditions of CRFR2 stimulation should further clarify the role of these signalling pathways.

While exogenous urocortin 1 administration can stimulate pituitary growth hormone release [39], the mechanism by which IGF-1 production is stimulated in $U c n 3^{+}$mice is more likely to be paracrine. Neither serum growth hormone nor hepatic IGF-1 levels were increased in $U_{c n} 3^{+}$mice. It is possible that subtle differences in growth hormone may have been missed on the single time point sample due to the pulsatile nature of growth hormone secretion. However, while growth hormone or Igfl transgenic mice show organomegaly and other aspects of an acromegalic phenotype [40, 41], transgenic mice overexpressing Igfl specifically within muscle show myofibre hypertrophy without systemic features of acromegaly [42, 43]. CRFR2 agonists ameliorate muscle atrophy in a variety of pathological conditions, including denervation atrophy and cancer cachexia, and will also increase mass of normal muscles [44-46]. While the mechanisms underlying this effect have not been described, it has been shown to be a paracrine effect, strongly suggesting that urocortin 3 acting locally at CRFR2 is responsible for the myocyte hypertrophy observed in $U c n 3^{+}$mice. IGF-1 produced within skeletal muscle appears to be released to the circulation, but this source is a minor contributor in comparison to liver [47]. The source of the small increase in serum IGF-1 in $U c n 3^{+}$mice is thus likely to be their increased muscle content.

Beneficial effects of IGF-1 in type 2 diabetes and other insulin-resistant states have been observed [37, 48]. Decreased hepatic gluconeogenesis contributes to this; however, liver contains no IGF-1 receptors and the main effect of IGF-1 is mediated in skeletal muscle, with effects on liver metabolism being secondary [49]. Likewise, evidence for altered hepatic fuel metabolism is seen in $\mathrm{Ucn}^{+}{ }^{+}$mice when CRFR2 has not been demonstrated in hepatocytes [50]. The $U c n 3^{+}$liver phenotype is apparently one of increased fatty acid oxidation and gluconeogenesis, which would seem appropriate compensatory adaptations for the increased fuel catabolism in muscle tissue. The Crfr2-knockout phenotype has been ascribed to increased sympathetic drive from the central nervous system upregulating brown adipose tissue UCP1 [10]. However, this does not seem to be occurring in $U_{c n} 3^{+}$mice. Nevertheless, altered sympathetic drive to splanchnic organs including liver cannot be entirely ruled out as contributing in part to their phenotype.

Overall, $U c n 3^{+}$mice demonstrate that CRFR2 can drive skeletal muscle hypertrophy and glucose uptake even in the face of dietary challenge. CRFR2 agonists may be useful therapies to maintain muscle mass and bypass the muscle insulin resistance that so commonly occurs, most notably with ageing.

Acknowledgements This work was supported by NIH Award DK26741, and in part by the Adler Foundation, Clayton Medical Research Foundation, Kleberg Foundation, Wellcome Trust, Israel Science Foundation, Israel Ministry of Health, the EC 6th Framework Programme, LSHM-CT-2003-503474 and the Division of Signal Transduction Therapy at the University of Dundee, funded by AstraZeneca, Boehringer-Ingelheim, GlaxoSmithKline, Merck KGaA and Pfizer. We thank the UAB Small Animal Phenotyping Core for body composition analysis (NIH DK56336, DK079626, NS057098) and J. Wingate for excellent technical assistance. W. W. Vale is a CMRF Senior Investigator.

Duality of interest W. W. Vale is a co-founder, member of the Board of Directors and shareholder of Neurocrine Biosciences. All other authors declare that there is no duality of interest associated with this manuscript. 
Open Access This article is distributed under the terms of the Creative Commons Attribution Noncommercial License which permits any noncommercial use, distribution, and reproduction in any medium, provided the original author(s) and source are credited.

\section{References}

1. Lovenberg TW, Liaw CW, Grigoriadis DE et al (1995) Cloning and characterization of a functionally distinct corticotropinreleasing factor receptor subtype from rat brain. Proc Natl Acad Sci USA 92:836-840

2. Vaughan JM, Donaldson C, Bittencourt J et al (1995) Urocortin, a mammalian neuropeptide related to fish urotensin I and to corticotropin-releasing factor. Nature 378:287-292

3. Reyes TM, Lewis K, Perrin MH et al (2001) Urocortin II: a member of the corticotropin-releasing factor (CRF) neuropeptide family that is selectively bound by type 2 CRF receptors. Proc Natl Acad Sci USA 98:2843-2848

4. Lewis K, Li C, Perrin MH et al (2001) Identification of Urocortin III, an additional member of the corticotropin-releasing factor (CRF) family with high affinity for the CRF2 receptor. Proc Natl Acad Sci USA 98:7570-7575

5. Hsu SY, Hsueh AJ (2001) Human stresscopin and stresscopinrelated peptide are selective ligands for the type 2 corticotropinreleasing hormone receptor. Nat Med 7:605-611

6. Reul JM, Holsboer F (2002) Corticotropin-releasing factor receptors 1 and 2 in anxiety and depression. Curr Opin Pharmacol 2:23-33

7. Broberger C (2005) Brain regulation of food intake and appetite: molecules and networks. J Intern Med 258:301-327

8. Black PH (2006) The inflammatory consequences of psychologic stress: relationship to insulin resistance, obesity, atherosclerosis and diabetes mellitus, type II. Med Hypotheses 67:879-891

9. Bale TL, Anderson KR, Roberts A, Lee K-F, Nagy TR, Vale WW (2003) Corticotropin-releasing factor receptor-2 deficient mice display abnormal homeostatic responses to challenges of increased dietary fat and cold. Endocrinology 144:2580-2587

10. Carlin KM, Vale WW, Bale TL (2006) Vital functions of corticotropin-releasing factor (CRF) pathways in maintenance and regulation of energy homeostasis. Proc Natl Acad Sci USA 103:3462-3467

11. Chen A, Brar B, Choi CS et al (2006) Urocortin 2 modulates glucose utilization and insulin sensitivity in skeletal muscle. Proc Natl Acad Sci USA 103:16580-16585

12. Li C, Chen P, Vaughan J et al (2003) Urocortin III is expressed in pancreatic beta-cells and stimulates insulin and glucagon secretion. Endocrinology 144:3216-3224

13. Solinas G, Summermatter S, Mainieri D et al (2006) Corticotropin-releasing hormone directly stimulates thermogenesis in skeletal muscle possibly through substrate cycling between de novo lipogenesis and lipid oxidation. Endocrinology 147:31-38

14. Li C, Chen P, Vaughan J, Lee KF, Vale W (2007) Urocortin 3 regulates glucose-stimulated insulin secretion and energy homeostasis. Proc Natl Acad Sci USA 104:4206-4211

15. Bale TL, Contarino A, Smith GW et al (2000) Mice deficient for corticotropin-releasing hormone receptor-2 display anxiety-like behaviour and are hypersensitive to stress. Nat Gen 24:410-414

16. Nagy TR, Clair AL (2000) Precision and accuracy of dual-energy $\mathrm{X}$-ray absorptiometry for determining in vivo body composition of mice. Obes Res 8:392-398

17. Brooke MH, Kaiser KK (1970) Muscle fiber types: how many and what kind? Arch Neurol 23:369-379
18. Sokoloff L, Reivich M, Kennedy C et al (1977) The $\left[{ }^{14} \mathrm{C}\right]$ deoxyglucose method for the measurement of local cerebral glucose utilization: theory, procedure, and normal values in the conscious and anesthetized albino rat. J Neurochem 28:897-916

19. Cleasby ME, Davey JR, Reinten TA et al (2005) Acute bidirectional manipulation of muscle glucose uptake by in vivo electrotransfer of constructs targeting glucose transporter genes. Diabetes 54:2702-2711

20. Chan TM, Exton JH (1976) A rapid method for the determination of glycogen content and radioactivity in small quantities of tissue or isolated hepatocytes. Anal Biochem 71:96-105

21. Kim HJ, Higashimori T, Park SY et al (2004) Differential effects of interleukin- 6 and -10 on skeletal muscle and liver insulin action in vivo. Diabetes 53:1060-1067

22. Jamieson PM, Nyirenda MJ, Walker BR, Chapman KE, Seckl JR (1999) Interactions between oestradiol and glucocorticoid regulatory effects on liver-specific glucocorticoid-inducible genes: possible evidence for a role of hepatic 11beta-hydroxysteroid dehydrogenase type 1. J Endocrinol 160:103-109

23. Jamieson PM, Chapman KE, Edwards CR, Seckl JR (1995) 11 beta-Hydroxysteroid dehydrogenase is an exclusive 11 betareductase in primary cultures of rat hepatocytes: effect of physicochemical and hormonal manipulations. Endocrinology 136:4754-4761

24. Richter EA, Ruderman NB (2009) AMPK and the biochemistry of exercise: implications for human health and disease. Biochem J 418:261-275

25. Livesey G, Elia M (1988) Estimation of energy expenditure, net carbohydrate utilization, and net fat oxidation and synthesis by indirect calorimetry: evaluation of errors with special reference to the detailed composition of fuels. Am J Clin Nutr 47:608-628

26. Bezaire V, Seifert EL, Harper ME (2007) Uncoupling protein-3: clues in an ongoing mitochondrial mystery. FASEB J 21:312-324

27. Brand MD, Esteves TC (2005) Physiological functions of the mitochondrial uncoupling proteins UCP2 and UCP3. Cell Metab 2:85-93

28. Bezaire V, Spriet LL, Campbell S et al (2005) Constitutive UCP3 overexpression at physiological levels increases mouse skeletal muscle capacity for fatty acid transport and oxidation. FASEB J 19:977-979

29. Li B, Nolte LA, Ju JS et al (2000) Skeletal muscle respiratory uncoupling prevents diet-induced obesity and insulin resistance in mice. Nat Med 6:1115-1120

30. Tsuboyama-Kasaoka N, Tsunoda N, Maruyama K et al (1999) Overexpression of GLUT4 in mice causes up-regulation of UCP3 mRNA in skeletal muscle. Biochem Biophys Res Commun 258:187-193

31. Dilger AC, Spurlock ME, Grant AL, Gerrard DE (2010) Myostatin null mice respond differently to dietary-induced and genetic obesity. Anim Sci J 81:586-593

32. Schmitz F, Hartmann H, Stumpel F, Creutzfeldt W (1991) In vivo metabolic action of insulin-like growth factor I in adult rats. Diabetologia 34:144-149

33. Dimitriadis G, Parry-Billings M, Bevan S et al (1992) Effects of insulin-like growth factor I on the rates of glucose transport and utilization in rat skeletal muscle in vitro. Biochem J 285(Pt 1):269-274

34. Di Cola G, Cool MH, Accili D (1997) Hypoglycemic effect of insulin-like growth factor-1 in mice lacking insulin receptors. $\mathrm{J}$ Clin Invest 99:2538-2544

35. Semsarian C, Wu MJ, Ju YK et al (1999) Skeletal muscle hypertrophy is mediated by a $\mathrm{Ca}^{2+}$-dependent calcineurin signalling pathway. Nature 400:576-581

36. LeBrasseur NK, Walsh K, Arany Z (2011) Metabolic benefits of resistance training and fast glycolytic skeletal muscle. Am J Physiol Endocrinol Metab 300:E3-E10 
37. Morrow LA, O’Brien MB, Moller DE, Flier JS, Moses AC (1994) Recombinant human insulin-like growth factor-I therapy improves glycemic control and insulin action in the type A syndrome of severe insulin resistance. J Clin Endocrinol Metab 79:205-210

38. Palazzolo I, Stack C, Kong L et al (2009) Overexpression of IGF-1 in muscle attenuates disease in a mouse model of spinal and bulbar muscular atrophy. Neuron 63:316-328

39. Holmberg BJ, Morrison CD, Keisler DH (2001) Endocrine responses of ovariectomized ewes to i.c.v. infusion of urocortin. J Endocrinol 171:517-524

40. Quaife CJ, Mathews LS, Pinkert CA, Hammer RE, Brinster RL, Palmiter RD (1989) Histopathology associated with elevated levels of growth hormone and insulin-like growth factor I in transgenic mice. Endocrinology 124:40-48

41. Mathews LS, Hammer RE, Behringer RR et al (1988) Growth enhancement of transgenic mice expressing human insulin-like growth factor I. Endocrinology 123:2827-2833

42. Coleman ME, DeMayo F, Yin KC et al (1995) Myogenic vector expression of insulin-like growth factor I stimulates muscle cell differentiation and myofiber hypertrophy in transgenic mice. J Biol Chem 270:12109-12116

43. Musaro A, McCullagh K, Paul A et al (2001) Localized Igf-1 transgene expression sustains hypertrophy and regeneration in senescent skeletal muscle. Nat Genet 27:195-200

44. Argiles JM, Figueras M, Ametller E et al (2008) Effects of CRF2R agonist on tumor growth and cachexia in mice implanted with Lewis lung carcinoma cells. Muscle Nerve 37:190-195

45. Hinkle RT, Donnelly E, Cody DB, Bauer MB, Sheldon RJ, Isfort RJ (2004) Corticotropin releasing factor 2 receptor agonists reduce the denervation-induced loss of rat skeletal muscle mass and force and increase non-atrophying skeletal muscle mass and force. J Muscle Res Cell Motil 25:539-547

46. Hinkle RT, Donnelly E, Cody DB et al (2003) Activation of the CRF 2 receptor modulates skeletal muscle mass under physiological and pathological conditions. Am J Physiol Endocrinol Metab 285: E889-E898

47. Shavlakadze T, Winn N, Rosenthal N, Grounds MD (2005) Reconciling data from transgenic mice that overexpress IGF-I specifically in skeletal muscle. Growth Horm IGF Res 15:4-18

48. Moses AC, Young SC, Morrow LA, O'Brien M, Clemmons DR (1996) Recombinant human insulin-like growth factor I increases insulin sensitivity and improves glycemic control in type II diabetes. Diabetes 45:91-100

49. Pennisi P, Gavrilova O, Setser-Portas J et al (2006) Recombinant human insulin-like growth factor-I treatment inhibits gluconeogenesis in a transgenic mouse model of type 2 diabetes mellitus. Endocrinology 147:2619-2630

50. Wang J, Xu Y, Zhu H, Zhang R, Zhang G, Li S (2008) Urocortin's inhibition of tumor growth and angiogenesis in hepatocellular carcinoma via corticotrophin-releasing factor receptor 2. Cancer Invest 26:359-368 